УДК 657.6

\title{
АУДИТ РАСЧЕТОВ С КОНТРАГЕНТАМИ В СЕЛЬСКОХОЗЯЙСТВЕННЫХ ОРГАНИЗАЦИЯХ
}

Лосева Алла Сергеевна к.э.н., доцент

Фецкович Игорь Владимирович к.э.Н., доцент ФГБОУ ВО Мичуринский ГАУ

Аннотация: В статье рассматриваются особенности аудиторской проверки расчетов с контрагентами в сельскохозяйственных организациях. Дается перечень контрагентов сельскохозяйственных организаций, выступающими ее деловыми партнерами. Сформулированы цель, задачи, источники информации, аудиторские процедуры и методы аудита расчетов с контрагентами. Обоснованы предпосылки формирования мнения аудитора в ходе аудита расчетов с контрагентами.

Ключевые слова: сельскохозяйственные организации, аудит, аудитор, расчеты, контрагенты.

\section{AUDIT OF PAYMENTS WITH CONTRACTORS IN AGRICULTURAL ORGANIZATIONS}

\section{Loseva Alla Sergeevna Fetskovich Igor Vladimirovich}

\begin{abstract}
The article discusses the features of the audit of settlements with counterparties in agricultural organizations. A list of counterparties of agricultural organizations, acting as its business partners, is given. The purpose, objectives, sources of information, audit procedures and methods for auditing settlements with counterparties have been formulated. The prerequisites for the formation of the auditor's opinion during the audit of settlements with counterparties have been substantiated.

Key words: agricultural organizations, audit, auditor, settlements, counterparties.
\end{abstract}


Контрагентами выступают юридические или физические лица, являющиеся деловыми партнерами организации. С позиции гражданскоправовых отношений контрагентом выступает противоположная сторона юридического договора.

Необходимо отметить, что четкого определения понятию «контрагенты» в отечественном законодательстве нет. Под понятием «контрагенты» организации в настоящее время подразумеваются ее деловые партнеры, которыми выступают как юридические, так и физические лица (рисунок 1).

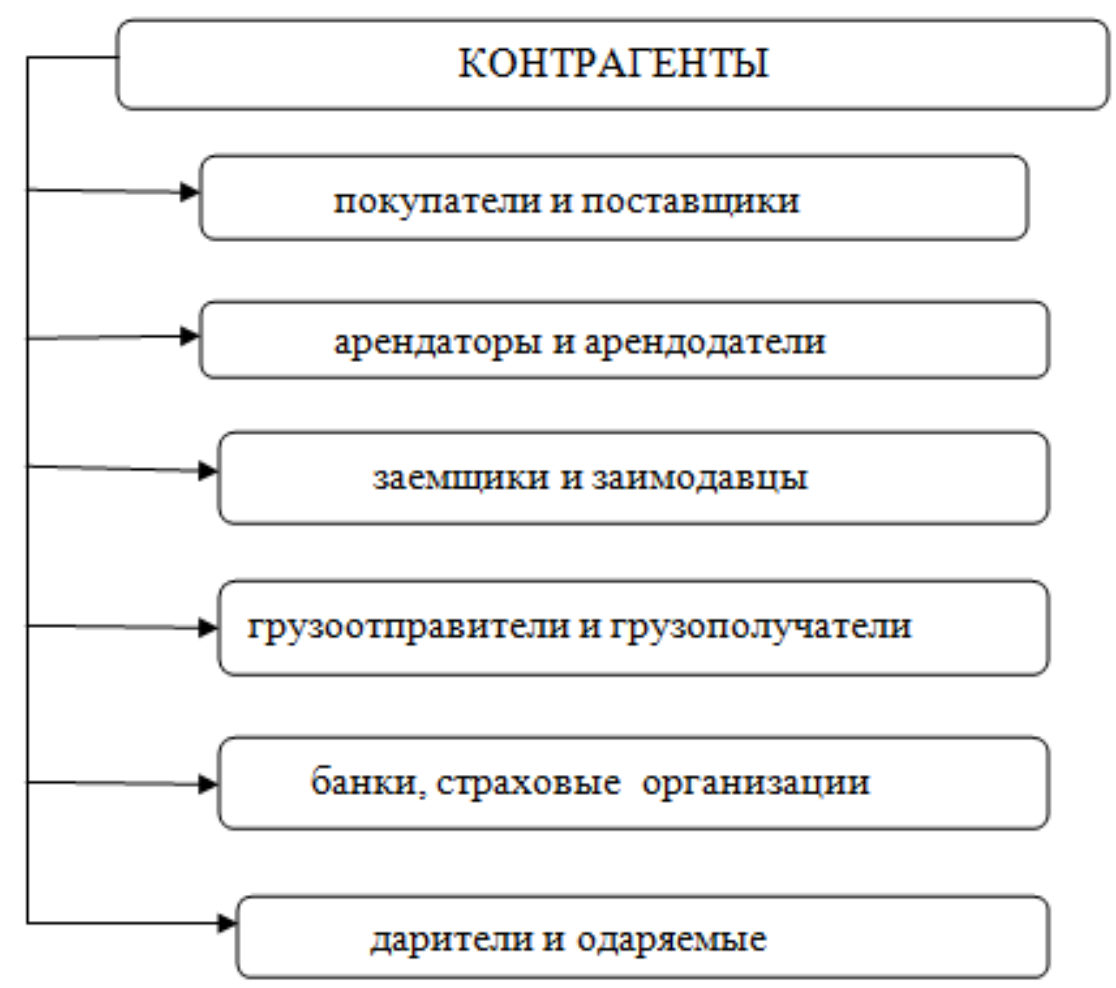

\section{Рис. 1. Контрагенты сельскохозяйственных организаций}

В настоящее время в сельскохозяйственных организациях расчеты с контрагентами представляют собой особую область бухгалтерского финансового учета, которая содержит в себе значительные хозяйственные риски. Эти риски напрямую связаны с риском неисполнения условий договора, с несвоевременным погашением кредиторской и дебиторской задолженности, что может привести, в конечном счете, к ощутимым финансовым потерям.

Это обуславливает необходимость осуществления особого тщательного контроля, в том числе внешнего, осуществляемого аудиторскими 
организациями (индивидуальными аудиторами) в части проверки достоверности статей бухгалтерского учета по расчетам с контрагентами.

Как результат реализации производственной деятельности, так и стабильность развития организации в обозримом будущем, зависят от выбора формы расчетов и ее соответствия конкретным условиям деятельности сельскохозяйственных организациях; грамотной организации документооборота и ведения учетного процесса, четкости соблюдения кредитной и ценовой политики, а также своевременности исполнения возникающих обязательств [1] .

В настоящее время расчеты с контрагентами в сельскохозяйственных организациях выступают неотъемлемой составляющей товарно-денежных отношений, образующихся в процессе производства и доведение готовой продукции до конечных потребителей [2].

В условиях российской экономики у сельскохозяйственных организаций отсутствуют ограничения в отношении выбора партнера по бизнесу, формы расчетных операций и формирования рынка сбыта готовой продукции, поэтому риск возникновения просроченной задолженности присутствует практически во всех экономических взаимоотношениях.

В целях предупреждения и устранения кризисных ситуаций возникает острая необходимость в использовании эффективных контрольных механизмов экономического контроля и управления расчетами с контрагентами, определяющие потенциальные риски и соответствующие действия, связанные с их устранением.

Это требует формирования особой информационной базы и научнообоснованной методики аудита расчётов с контрагентами.

Важным информационным источником аудита является бухгалтерский учет как специализированная информационная технология, направленная на удовлетворение запросов внутренних и внешних пользователей в учетной информации. Конечным продуктом функционирования такой технологии является бухгалтерская отчетность, с помощью которой отображаются состояние и результаты деятельности институциональных единиц [3].

Отечественными и зарубежными экономистами разработано и предложено достаточно методик проведения аудиторской проверки расчетов с контрагентами, направленные на решение многих вопросов и проблем создания действенного механизма экономического контроля. 
Однако они нуждаются в дополнительных глубоких, сосредоточенных исследованиях и доработках, отвечающих современным требованиям международных стандартов аудита [5].

Наряду с доработкой существующих теоретических и нормативных аспектов аудита расчетов с контрагентами, требуется разработка базисных методических разработок по эффективному развитию методического обеспечения аудита расчетов с контрагентами в сельскохозяйственных организациях, в части документирования, оценки качества информации в рамках системного подхода к аудиту, применения аналитических процедур.

Важнейшей задачей проведения аудита расчетов с контрагентами в сельскохозяйственных организациях является проверка реальности отражения, объективности, достоверности, правильности определения вероятности ее возврата [6].

Методика проведения аудиторской проверки расчетов с контрагентами в сельскохозяйственных организациях представляет собой определенную научно-обоснованную последовательность на каждом отдельном этапе проведения аудиторского контроля, включающие определение источников получения аудиторской информации, необходимой для формирования объективного профессионального мнения аудита, последовательность использования аналитических процедур и отражения полученных сведений в рабочих документах.

Методическое обеспечение и аудита расчетов с контрагентами в сельскохозяйственных организациях выступает как установленная внутрифирменными аудиторскими стандартами совокупность приемов практической деятельности непосредственно в ходе проверки, приводящая к определенному желаемому достоверному результату с учетом аудиторского риска [8].

Можно утверждать, что принятая внутрифирменными стандартами методика аудиторской проверки расчетов с контрагентами в сельскохозяйственных организациях обуславливает, прежде всего, сформированный порядок принятия решений по промежуточным результатам аудиторской проверки и конкретную форму передачи проверяемому экономическому субъекту заключительных документов (аудиторского заключения, отчета по результатам проверки).

Кроме того, методика аудита расчетов с контрагентами в сельскохозяйственных организациях должна предусматривать и участие 
аудиторской организации (индивидуального аудитора) в представлении интересов хозяйствующего субъекта основе дальнейшего аудиторского сопровождения.

К основным методами аудиторской проверки расчетов с контрагентами в сельскохозяйственных организациях можно отнести:

-исследование учетных документов, регистрирующих формирование расчетов с контрагентами;

-проверку аналитических и синтетических регистров;

-экономический анализ;

-встречная, арифметическая, нормативная проверки;

-хронологический анализ;

-отслеживание;

-опрос;

-сканирование;

-наблюдение;

-анкетирование.

Каждая аудиторская организация (индивидуальный аудитор) самостоятельно формируют, развивают и используют в своей профессиональной деятельности современные и эффективные методики, используя весь свой опыт и разрабатывая внутрифирменные аудиторские стандарты, основываясь на международных стандартах аудита (MCA).

Цель функционирования методического обеспечения аудиторской проверки на данном участке сводится к обоснованию основных теоретических положений и выработки необходимых рекомендаций, направленных на динамичное развитие целостной системы для установления правильности и достоверности отражения расчетов с контрагентами при формировании финансовой отчетности сельскохозяйственных организаций [7].

В ходе аудиторской проверки расчетов с контрагентами в сельскохозяйственных организациях, выраженное аудитором профессиональное мнение в первую очередь будет учитывать следующие предпосылки, содержащиеся в отчетности:

-полнота раскрытия информации о состоянии расчетов с контрагентами организации;

-возникновение дебиторской и кредиторской задолженности в отчетном и прошлых периодах;

-классификация контрагентов и расчетов в разрезе каждого из них; 
-оценка дебиторской и кредиторской задолженности;

-порядок закрытия отчетного периода (таблица 1).

Таблица 1

Предпосылки формирования мнения аудитора в ходе аудита расчетов с контрагентами в сельскохозяйственных организациях

\begin{tabular}{|l|l|}
\hline $\begin{array}{l}\text { Предпосылки формирования мнения } \\
\text { аудитора }\end{array}$ & Содержание анализируемой предпосылки \\
\hline Полнота раскрытия и представления & $\begin{array}{l}\text { Сумма операций, связанных с расчетами с } \\
\text { контрагентами в бухгалтерском учете, полностью } \\
\text { соответствует фактически отраженной в отчетности }\end{array}$ \\
\hline $\begin{array}{l}\text { Возникновение в отчетном } \\
\text { и прошлых периодах }\end{array}$ & $\begin{array}{l}\text { Сумма отражена в регистрах бухгалтерского учета } \\
\text { операций по расчетам с контрагентами с учетом } \\
\text { отчетного и прошлых периодов }\end{array}$ \\
\hline Оценка в учете & $\begin{array}{l}\text { Сумма операций с контрагентами отражена в } \\
\text { регистрах бухгалтерского учета и отчетности верно }\end{array}$ \\
\hline $\begin{array}{l}\text { Порядок закрытия отчетного } \\
\text { периода }\end{array}$ & $\begin{array}{l}\text { Сумма операций с контрагентами, отраженная в } \\
\text { отчетности, в реальности существует на дату } \\
\text { составления баланса, а период применения его } \\
\text { стоимости является верным }\end{array}$ \\
\hline Классификация в учете & $\begin{array}{l}\text { Составляющие элементы дебиторской и } \\
\text { кредиторской задолженности по расчетам с } \\
\text { контрагентами классифицированы в бухгалтерском } \\
\text { учете правильно }\end{array}$ \\
\hline Понятность для пользователя & $\begin{array}{l}\text { Сумма операций по расчетам с контрагентами в } \\
\text { бухгалтерской отчетности представлена в доступной } \\
\text { для внешнего пользователя форме }\end{array}$ \\
\hline
\end{tabular}

Предпосылка, касающаяся полноты раскрытия и представления, предполагает, что стоимость дебиторской и кредиторской задолженности в бухгалтерском учете полностью соответствует фактически отраженной в бухгалтерской (финансовой) отчетности сельскохозяйственной организации.

Возникновение предполагает, что сумма дебиторской и кредиторской задолженности верно и вовремя отражена в регистрах бухгалтерского учета с учетом отчетного и прошлых периодов, исследуемых в ходе аудиторской проверки [10].

Оценка в бухгалтерском учете предполагает, что сумма расчетных операций с контрагентами отражена в регистрах бухгалтерского учета и бухгалтерской (финансовой) отчетности верно. 
Изучение аудитором действующего в сельскохозяйственной организации порядка закрытия проверяемого отчетного периода производится путем исследования фактической суммы операций по расчетам с контрагентами, отраженной в отчетности.

Важным моментом выступает процесс, когда аудитор устанавливает реальность существования сумм операций по расчётам с контрагентами на дату составления баланса.

Предпосылка формирования мнения аудитора, основанная на выводах аудитора на основе изучения составляющих элементов дебиторской и кредиторской задолженности, позволяет определить, правильно ли осуществлена ее классификация.

Аудитор должен убедиться, что сумма операций по расчетам с контрагентами в бухгалтерской отчетности представлена в доступной, ясной и понятной для внешнего пользователя форме.

В процессе аудиторской проверки устанавливается, что отраженная в бухгалтерской (финансовой) отчетности коммерческой организации АПК сумма дебиторская задолженности представлена исключительно по реальным хозяйственным операциям.

Указанный факт может быть подтвержден предъявлением первичных учётных документов.

Тщательной проверке подвергается формирование и своевременность погашения расчетных операций с контрагентами, а также правильность разграничения по анализируемым проверяемым периодам [11].

Используя данные заключенных договоров поставки, платежных поручений, счетов фактур на оплату товаров, аудитор устанавливает и подтверждает факт покупки товаров.

При этом сумма полученной выручки сельскохозяйственной организацией должна отражаться по моменту отгрузки (переходу права собственности на товар), что можно подтвердить проверкой соответствующих товарных накладных.

Внешним аудитором может быть проведена экспресс- оценка возникшей вероятности возникновения признанной безнадежной задолженности разных дебиторов.

Проводимая аудитором экспресс-оценка дает возможность составить прогнозные расчеты по поступлениям денежных средств в разрезе каждого контрагента [13]. 
Кроме того, экспресс-оценка оценка позволяет выявить покупателей, к которым необходимо применить специальные мероприятия по возврату неуплаченной задолженности и провести общую оценку эффективности управления дебиторской задолженностью в целом по сельскохозяйственной организации.

В ходе аудиторской проверки аудитор устанавливает правильность списание задолженности с истекшими сроками исковой давности путем формирования реестров старения кредиторской и дебиторской задолженностей.

Необходимо отметить, что конкретные формы реестров разрабатываются непосредственно аудиторскими организациями (индивидуальными аудиторами).

Регистры старения задолженностей позволяют проводить ранжирование обязательств и требований по срокам взыскания и погашения задолженности.

Как правило, аудитор особое внимание уделяет проверке существенных (значимых) сумм, подлежащих к взысканию с конкретного дебитора.

Кроме того, аудиторская организация (индивидуальный аудитор) должен удостовериться, чтобы в состав стоимости дебиторской задолженности не входили долги организаций-банкротов, которые ранее были исключены из государственного реестра [12].

Наряду с этим аудитор проверяет, чтобы в состав задолженности сельскохозяйственно организации не были включены просроченные суммы, причитающиеся к уплате по исполнительным листам соответствующих органов.

Необходимо убедиться, что списание сумм дебиторской задолженности должно быть произведено на основании соответствующего приказа либо распоряжения руководителя сельскохозяйственной организации.

Обязательным моментом в ходе аудиторской проверки на данном участке выступает проверка документальной обоснованности произведенных хозяйственных операций, связанных с образованием расчетов с контрагентами.

В случае если в договорах между контрагентами прописаны финансовые санкции в виде штрафов, пеней, неустоек, аудитору необходимо предусмотреть следующие процедуры:

-проверку обоснованности штрафных санкций, предъявленных при нарушении договора;

-установление обоснованности претензий, которые предъявляются организации; 
-изучение организации аналитического учета в разрезе каждого дебитора;

-проверку правильности отражения операций на счетах бухгалтерского учета (рисунок 2) .

Степень доверия аудитора к сформированным результатам аналитических процедур в ходе аудита расчетов с контрагентами напрямую зависит от следующих условий:

-значимости полученной информации по счетам расчетов с контрагентами;

-представленного набора аудиторских процедур, способствующих повышению доверия к результатам проведенной проверки;

-степени точности полученных результатов;

-проведения оценок возможных аудиторских рисков.

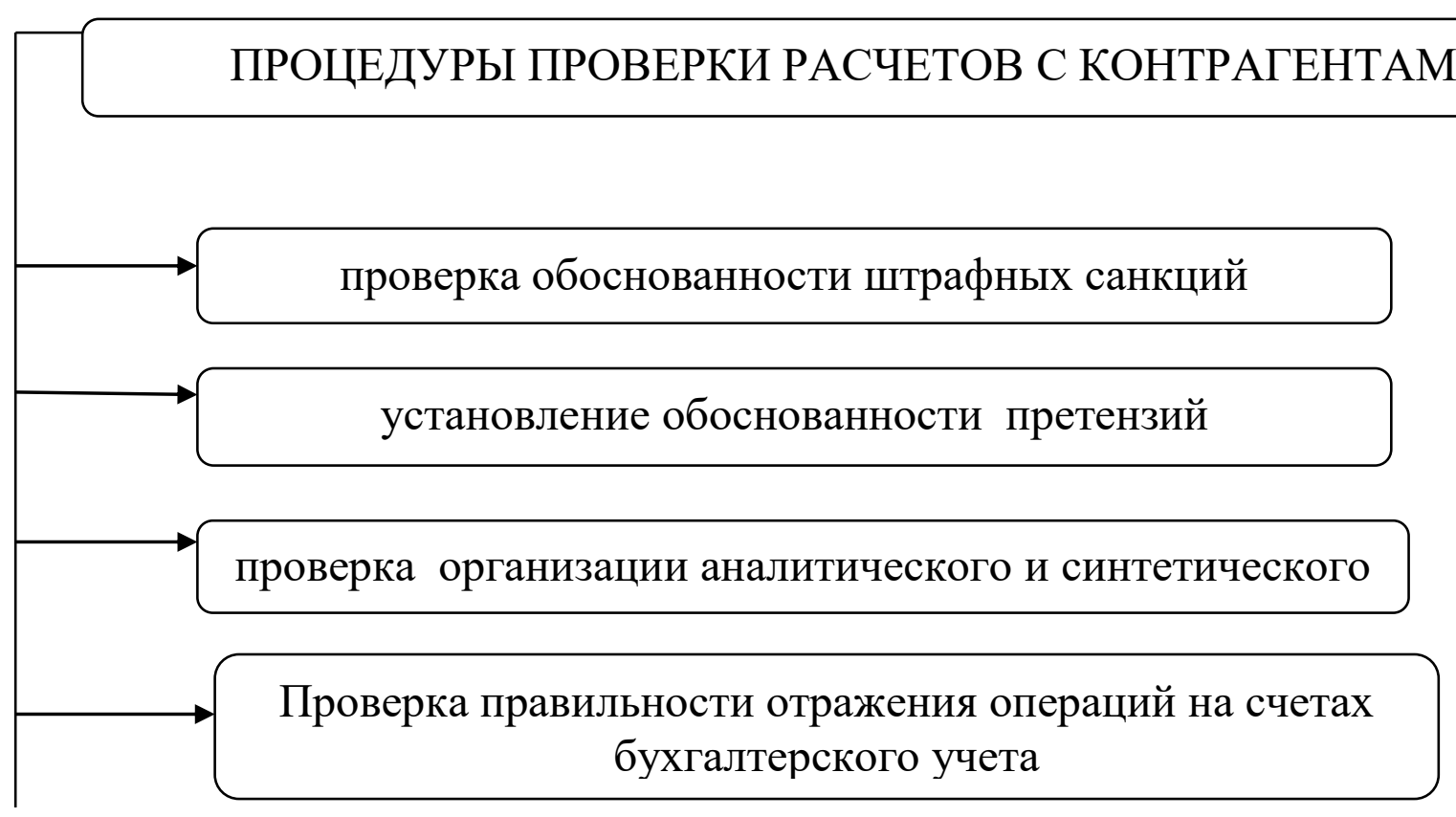

Рис. 2. Аудиторские процедуры в ходе проверки расчетов с контрагентами в случае наличия в договоре финансовых санкций

Результативность аналитических процедур ходе аудиторской проверки расчетов с контрагентами в сельскохозяйственных организациях будет зависеть, прежде всего, от степени детализации проводимых действий (таблица 2).

Как показывают расчеты, коэффициент оборачиваемости дебиторской задолженности в СХПК «Гладышевский» неуклонно растет, что является 
положительным фактором и говорит об улучшении расчетов и организации работы с дебиторами.

Соответственно, уменьшается срок погашения дебиторской задолженности, тор есть время, в течение которого организация ожидает денег за отгруженную готовую продукцию собственного производства.

Этап планирования аудита расчётов с контрагентами в сельскохозяйственных организациях является обязательным и необходимым.

Таблица 2 Аналитическая процедура «Оборачиваемость дебиторской задолженности СХПК «Гладышевский» Токаревского района Тамбовской области за 2017 - 2019 гг.

\begin{tabular}{|l|l|l|l|}
\hline Показатель & 2017 г. & 2018 г. & 2019 г. \\
\hline Средняя величина дебиторской задолженности, тыс. руб. & 4017,50 & 4681,60 & 4706,50 \\
\hline Коэффициент оборачиваемости дебиторской задолженности & 1,18 & 1,22 & 1,32 \\
\hline Срок погашения дебиторской задолженности, дн. & 305 & 295 & 272 \\
\hline
\end{tabular}

Он включает в себя положения, касающиеся оценки объема планируемого аудита расчетов с контрагентами, разработки плана и программы, а также планируемые аудиторские процедуры.

Мнение аудитора, касающееся организации бухгалтерского учета расчетов с контрагентами в сельскохозяйственных организациях, является веским основанием для принятия решения о проведении выборочных проверок, а также определения возможности проведения детализации планируемых аудиторских процедур.

Мониторинг качества учётной информации выступает специфическим элементом системы оценки качества учетной информации при аудите расчетов с контрагентами.

Модель организационной структуры оценки качества учетной информации при аудите расчетов с контрагентами в сельскохозяйственных организациях предусматривает разработку и использование системы частных, промежуточных показателей и агрегированного общего критерия эффективности системы мониторинга. 
Таким образом, важнейшими направлениями развития методического обеспечения аудита расчетов с контрагентами в сельскохозяйственных организациях выступают:

-грамотное планирование аудиторской работы, позволяющее разработать оптимальную стратегию и тактику проведения аудита с учетом индивидуальных особенностей сельскохозяйственного производства;

- совершенствование документирования аудита на основе использования новых форм рабочих документов, способствующих детализации аудиторских процедур;

- использование модели организационной структуры оценки качества учетной информации на основе взаимодействия ее элементов: внутреннего и внешнего контроля, а также системы мониторинга качества информации.

\section{Список литературы}

1. Гусева А.С. Эффективность функционирования масложирового подкомплекса в условиях развития интеграционных процессов (на материалах Тамбовской области): диссертация кандидата экономических наук / Мичуринский государственный аграрный университет. - Мичуринск: Наукоград РФ, 2008

2. Дубовицкий А.А. Ключевые ориентиры экономического развития малого агробизнеса / Дубовицкий А.А., Климентова Э.А. // Экономика сельскохозяйственных и перерабатывающих предприятий. -2019. - № 12. C. 89-94.

3. Лосева А.С., Мегаева С.В. Современные проблемы бухгалтерского учета в организациях АПК: учеб. пособие / А.С. Лосева, С.В. Мегаева. Мичуринск: Издательство Мичуринского ГАУ, 2019. - 119 с.

4. Лосева, А.С., Фецкович, И.В. Внутренний аудит и анализ готовой продукции в коммерческих организациях агропромышленного комплекса // Тенденции развития науки и образования. - 2019 - №55-9. - С.75-78

5. Лосева, А.С., Фецкович, И.В. Использование системного подхода к оценке качества информации в бухгалтерском учете и аудите // Наука и бизнес: пути развития. - 2019. - №5 (95). - С. 95-97.

6. Лосева, А.С., Фецкович И.В., Попова В.Б. Современные аспекты бухгалтерского учета основных средств // Агротехнологии XXI века: материалы Всероссийской научно-практической конференции с международным участием, 
"Пермский государственный аграрно-технологический университет имени академика Д.Н. Прянишникова". 2019. С. 60-64.

7. Лосева А.С. Роль финансового контроля в обеспечении экономической безопасности на предприятиях. Инновационные достижения науки и техники АПК: научные труды Международной научно-практической конференции, 2018. - C. 511-514.

8. Лосева, А.С., Фецкович, И.В. Тенденции и перспективы развития аудита в Российской Федерации / А.С. Лосева, И.В. Фецкович // KANT. - 2018. - №1(26). - С. 326-329.

9. Лосева, А.С. Совершенствование методики аудита основных средств в коммерческих предприятиях / A.C. Лосева, И.В. Фецкович // Журнал KANT, №1 (26) - 2018 г., изд-во «Ставролит», Ставрополь, С.195-198

10. Лосева. А.С. Развитие экологического учета на предприятиях масложировой промышленности / И.В. Фецкович, А.С. Лосева // Технологии пищевой и перерабатывающей промышленности АПК продукты здорового питания. - 2017. - №2 (16). - С.92-99

11. Лосева А.С. Совершенствование аудиторской проверки расчетов с контрагентами в сельскохозяйственных организациях. Europeans Scientific conference: сборник статей победителей III Международной научнопрактической конференции, 2017. - С. 11-13.

12. Лосева А.С., Фецкович И.В. Развитие экологического учета и анализа на предприятиях агропромышленного комплекса // Лучшая научноисследовательская работа: сб. статей VI междунар. науч.-прак. конкурсаПенза: МЦНС «Наука и Просвещение», 2017. - С. 69-72

13. Шаляпина, И.П. Состояние и эффективность масложировой промышленности в Тамбовской области / И.П Шаляпина, А.С. Гусева // Экономика сельскохозяйственных и перерабатывающих предприятий. - 2007. № 10. - С. $85-88$.

(С) А.С. Лосева, И.В. Фецкович, 2020 